\title{
Penggunaan Penyaring Air Serbaguna Bio-Multi Filter Model Sarang Tawon Sebagai Penjernih Air di Desa Bukit Rawi Kecamatan Kahayan Tengah Kabupaten Pulang Pisau
}

\author{
Allan Restu Jaya*, I Made Kamiana, Hendro Suyanto, Haiki Mart Yupi, \\ Dwi Anung Nindito, Raden Haryo Saputra, Nomeritae \\ Program Studi Teknik Sipil, Fakultas Teknik UPR \\ *Penulis Korespondensi: allanrestujaya@gmail.com
}

\begin{abstract}
Abstrak
Ketersediaan air bersih di pedesaan secara umum, masih dirasakan kurang termasuk di Desa Bukit Rawi, Kecamatan Kahayan Tengah, Kabupaten Pulang Pisau, terutama terkait pemanfaatan sumber daya air yang berasal dari Sungai Kahayan, hal itu disebabkan keadaan air bakunya secara fisik masih terlihat keruh dan berwarna kecokelatan. Oleh karena itu, untuk dapat memenuhi kebutuhan air bersih masyarakat setempat perlu dilakukan upaya agar air bisa lebih baik dan lebih jernih secara fisik khususnya untuk air baku dari Sungai Kahayan, yaitu dengan cara menerapkan teknologi tepat guna berupa Penyaringan Air Serbaguna Bio-Multi Filter Model Sarang Tawon. Dalam rangka ikut membantu terwujudnya air bersih yang baik sehingga mampu meningkatkan derajat kesehatan masyarakat, maka sebagai bentuk implementasi Tri Dharma Perguruan Tinggi, dosen UPR berperan aktif dalam pengabdian kepada masyarakat melalui program penerapan teknologi tepat guna untuk masyarakat dengan memberikan Penyaring Air Serbaguna untuk melindungi masyarakat dari penyakit yang berasal dari air yang dikonsumsi. Target dari pelaksanaan pengabdian kepada masyarakat ini adalah masyarakat Desa Bukit Rawi. Metode yang digunakan adalah demonstrasi pembuatan dan pemakaian alat serta serah terima alat sebagai solusi kepada mitra yaitu masyarakat Desa Bukit Rawi. Kesimpulan dari program pengabdian ini dengan adanya pemanfaatan Penyaring Air Serbaguna Bio-Multi Filter Model Sarang Tawon di desa dapat meningkatkan derajat kesehatan masyarakat terutama berkaitan dengan tersedianya air yang bersih dan jernih.
\end{abstract}

Kata kunci : Air baku, air bersih, teknologi tepat guna, penyaring air

\section{PENDAHULUAN}

Desa Bukit Rawi merupakan salah satu Desa yang ada di Kecamatan Kahayan Tengah Kabupaten Pulang Pisau yang dalam kehidupan masyarakatnya juga sudah barang tentu sangat memerlukan air bersih. Dalam hal ini air bersih yang dimaksud adalah air yang layak untuk dipakai sebagai faktor yang mempengaruhi derajat kesehatan masyarakat di antaranya tingkat ekonomi, pendidikan, keadaan lingkungan, dan kehidupan sosial budaya. Faktor yang penting dan dominan dalam penentuan derajat kesehatan masyarakat adalah keadaan lingkungan. Salah satu komponen lingkungan yang mempunyai peranan yang cukup besar dalam kehidupan adalah air.

Masyarakat Desa Bukit Rawi ada yang menggunakan sumur artetis dan ada pula yang sudah menggunakan air dari PDAM sementara potensi air sungai juga adalah merupakan salah satu sumber air baku yang bisa dijadikan air bersih untuk masyarakat. Oleh karena itu mengingat di Desa Bukit Rawi adalah Desa yang terletak di pinggir Sungai Kahayan, maka perlu diberikan alternatif lain dari sumber air yang digunakan misalnya air dari Sungai Kahayan. Air baku dari Sungai Kahayan secara fisik terlihat keruh karena sudah terkontaminasi akibat sedimen dan kotoran yang terbawa dari hulu ke hilir sungai, sehingga dengan demikian diperlukan Teknologi Tepat Guna yang bisa menjernihkan air.

Dalam hal ini ditawarkan dan diperkenalkan salah satu Teknologi Tepat Guna berupa Alat Penyaring Air Serbaguna Bio-Multi Filter Model Sarang Tawon, yang merupakan hasil karya mahasiswa dan dosen dalam bidang air bersih. 
Konsep program pengabdian kepada masyarakat yang dilakukan oleh dosen adalah berupa demonstrasi pembuatan dan pemakaian alat serta serah terima alat sebagai solusi untuk mendapatkan air yang jernih di Desa Bukit Rawi Kecamatan Kahayan Tengah Kabupaten Pulang Pisau.

\section{METODE PELAKSANAAN}

Adapun metode pelaksanaan kegiatan ini menggunakan metode demonstrasi pembuatan dan pemakaian alat serta serah terima alat. Tahapannya adalah sebagai berikut:

\section{a. Tahap Persiapan}

Pada tahap ini tim pengusul melakukan observasi terhadap permasalahan yang ada di lokasi sejauh mana permasalahan tentang ketersediaan air yang jernih bisa di dapat oleh masyarakat, baik itu terhadap sumber air yang sudah ada maupun sumber air dari sungai. Terutama sumber air dari Sungai Kahayan. Bagaimana tingkat kekeruhannya apabila air tersebut belum dilakukan pengolahan dan bagaimana pula tingkat kekeruhan yang sudah sampai di masyarakat pengguna air. Hal ini dilakukan untuk mengetahui kondisi air yang dimanfaatkan oleh masyarakat di lokasi kegiatan. Pada tahap ini juga tim pengusul menyiapkan bahan-bahan dan peralatan yang digunakan dalam rangka pembuatan alat Penyaring Air Serbaguna Bio-Multi Filter Model

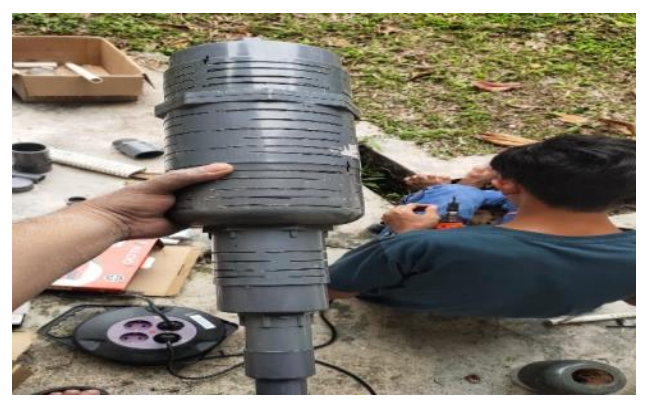

Sarang Tawon.

b. Tahap Pelaksanaan

Pada tahap ini dilakukan ceramah berupa penjelasan tentang cara pembuatan Alat Penyaring air serbaguna, di mana sebelumnya telah dilakukan terlebih dahulu identifikasi masalah dengan melakukan pengamatan lokasi. Selanjutnya dilakukan praktek uji coba Alat Penyaring Air yaitu dengan melakukan peragaan dan demonstrasi pembuatan, pemasangan dan pengoperasian Alat Penyaring Air pada beberapa orang peserta mewakili masyarakat setempat. Tujuan utama dari kegiatan ini adalah agar masyarakat yang ikut dalam kegiatan tersebut dapat membuat dan mengoperasikan Alat Penyaring Air secara mandiri. Pada saat praktek pembuatan dan pengoperasian Alat Penyaring ini, dilakukan pendampingan sehingga masyarakat Desa Bukit Rawi bisa dengan mudah memahaminya. Tahap berikutnya adalah penyerahan Alat Penyaring Air Serbaguna Bio-Multi Filter Model Sarang Tawon yang sudah dibuat untuk diserahkan kepada masyarakat Desa Bukit Rawi agar bisa dimanfaatkan dalam rangka pemenuhan kebutuhan air bersih yang jernih di Desa Bukit Rawi. Adapun Alat Penyaring Air dan kelengkapannya yang diserahkan yaitu berupa Alat Penyaring Air, Filter Air, Pompa Air, Tandon Air, dan tempat perletakan Penyaring Air.

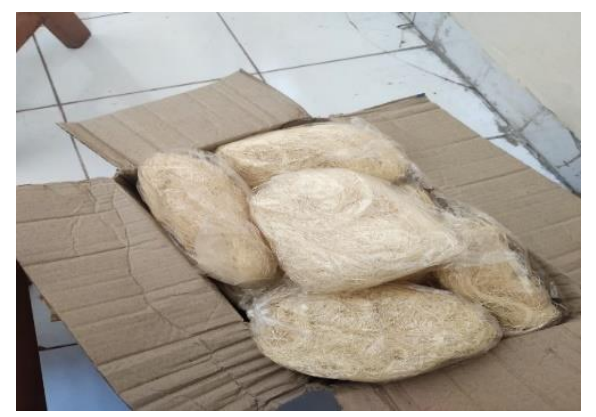

(b)

Gambar 1. (a) Alat Penyaring Air, (b) Filter Air 


\section{HASIL DAN PEMBAHASAN}

Demonstrasi cara pembuatan dan penggunaan Alat Penyaring Air Serbaguna, salah satunya adalah berupa penjelasan SOP penggunaan kepada pihak masyarakat Desa Bukit Rawi yang ditunjuk sebagai perwakilan yaitu perangkat desa, Badan Permusyawaratan Desa, Ketua RT, dan sebagian pengurus PKK. Ide pemberian Alat Penyaring Air ini adalah dari hasil penelitian dosen dan mahasiswa yang membuat inovasi berupa Teknologi Tepat Guna dalam rangka untuk menjernihkan air yang keruh sehingga menjadi produk air bersih yang layak dimanfaatkan oleh masyarakat.

Tak dapat dipungkiri bahwa sangat sering kita temukan air yang diambil dari sungai ataupun sumur banyak mengandung kotoran- kotoran, seperti pasir, bebatuan, atau partikel lainya. Sehingga diperlukan saringan air yang sederhana agar dapat digunakan masyarakat untuk membantu masyarakat dalam memenuhi kebutuhan air yang bersih. Dalam beberapa kasus memang sudah ada alat penyaring air yang mampu menyaring air dengan volume besar, tetapi waktu yang diperlukan masih cukup lama. Terkadang untuk kasus tertentu, kita perlu sistem penyaring yang mampu menyaring air dengan volume besar, namun dengan waktu yang cepat. Banyak sistem penyaring menggunakan bantuan pompa yang sudah ada, namun konsep yang diterapkan terkadang tidak ramah lingkungan. Jenis penyaring air yang ada, biasanya hanya mengunakan satu tahap proses penyaringan, sehingga dirasa kurang optimal.

Berdasarkan fakta dan permasalahan yang telah disebutkan di atas, barangkali perlu ada solusi untuk membuat sebuat inovasi Teknologi Tepat Guna (TTG) sistem penyaring air bersih yang mampu menyaring air dalam volume besar, namun waktu yang dibutuhkan cukup singkat, menggunakan filter yang ramah lingkungan dan memiliki mekanisme penyaringan yang dilakukan bertahap. Untuk itu ada ide dengan menggunakan konsep model sarang tawon yang kita ketahui bersama, memiliki tahapan lapis (dalam menyimpan madu). Konsep inilah yang melatar belakangi ide inovasi penyaring air ini.

\section{Tujuan dan Manfaat Alat}

Tujuan dan manfaat alat Bio-Multi Filter Model Sarang Tawon adalah sebagai berikut:

1. Alat ini diharapkan mampu menyaring air menggunakan konsep multifilter (multi tahap) dengan menggunakan bahan filter yang ramah lingkungan, seperti serat nanas, serat kelapa, serat pelepah pisang, arang aktif dan bahan alami lain (bio-filter lain).

2. Kebutuhan masyarakat akan air bersih untuk kebutuhan sehari- sehari menjadi terpenuhi, sehingga diharapkan dapat meningkatkan kesehatan masyarakat.

3. Memperlancar aktivitas masyarakat sehari - hari, mengingat air merupakan kebutuhan utama manusia. Dengan adanya akses air bersih mempermudah masyarakat untuk melaksanakan kegiatan sehari - hari, seperti memasak, mandi, mencuci, dan lain sebagainya.

4. Menghemat waktu dan tenaga, dengan adanya Bio-Multi Filter Model Sarang Tawon membuat waktu dan tenaga yang sebelumnya digunakan untuk mencari air bersih dapat digunakan untuk kegiatan lain.

5. Menghemat biaya, karena bahan yang digunakan berasal dari sekitar kita.

Adapun manfaat dari alat Bio-Multi Filter Model Sarang Tawon adalah sebagai berikut:

1. Untuk mengurangi kotoran-kotoran yang ada di dalam air, seperti pasir, bebatuan, atau partikel lainya.

2. Meningkatkan kebersihan air agar dapat digunakan langsung.

3. Air menjadi layak pakai dan layak guna.

\section{Cara Kerja}

Cara kerja dari Sistem Bio-Multi Filter Model Sarang Tawon, yaitu:

1. Pompa air dihidupkan.

2. Air yang berasal dari penampungan, masuk ke dalam filter penyaring. 
3. Air yang sudah disaring kemudian dipompa keluar dialirkan ke dalam penampungan air bersih.

4. Tahap 2 dan 3 akan berlangsung secara kontinu hingga seluruh air dalam penampungan menjadi bersih.

Mekanisme/cara kerja Bio-Multi Filter Model Sarang Tawon seperti ditunjukkan pada gambar dibawah ini.

\section{Kelebihan dan Kelemahan Alat}

Kelebihan dari alat Sistem Bio-Multi Filter Model Sarang Tawon, yaitu:

1. Menggunakan bahan penyaring yang mudah didapat (serat bio-alami), seperti serat Nanas, serat kelapa, serat pelepah pisang, dan arang aktif yang mudah didapat dan memiliki harga relatif murah dipasaran

2. Bahan pembuatan alat mudah didapat. Perakitan alat yang mudah dan praktis.

3. Alat yang sederhana sehingga cocok dipakai untuk skala rumahan.

4. Mudah digunakan, sehingga dapat digunakan oleh banyak orang.

5. Perawatan cukup mudah.

Kelemahan dari alat Sistem Bio-Multi Filter Model Sarang Tawon, yaitu membutuhkan sumber daya listrik untuk pompa air.

Proses ini dilakukan berulangulang selama proses penyaringan

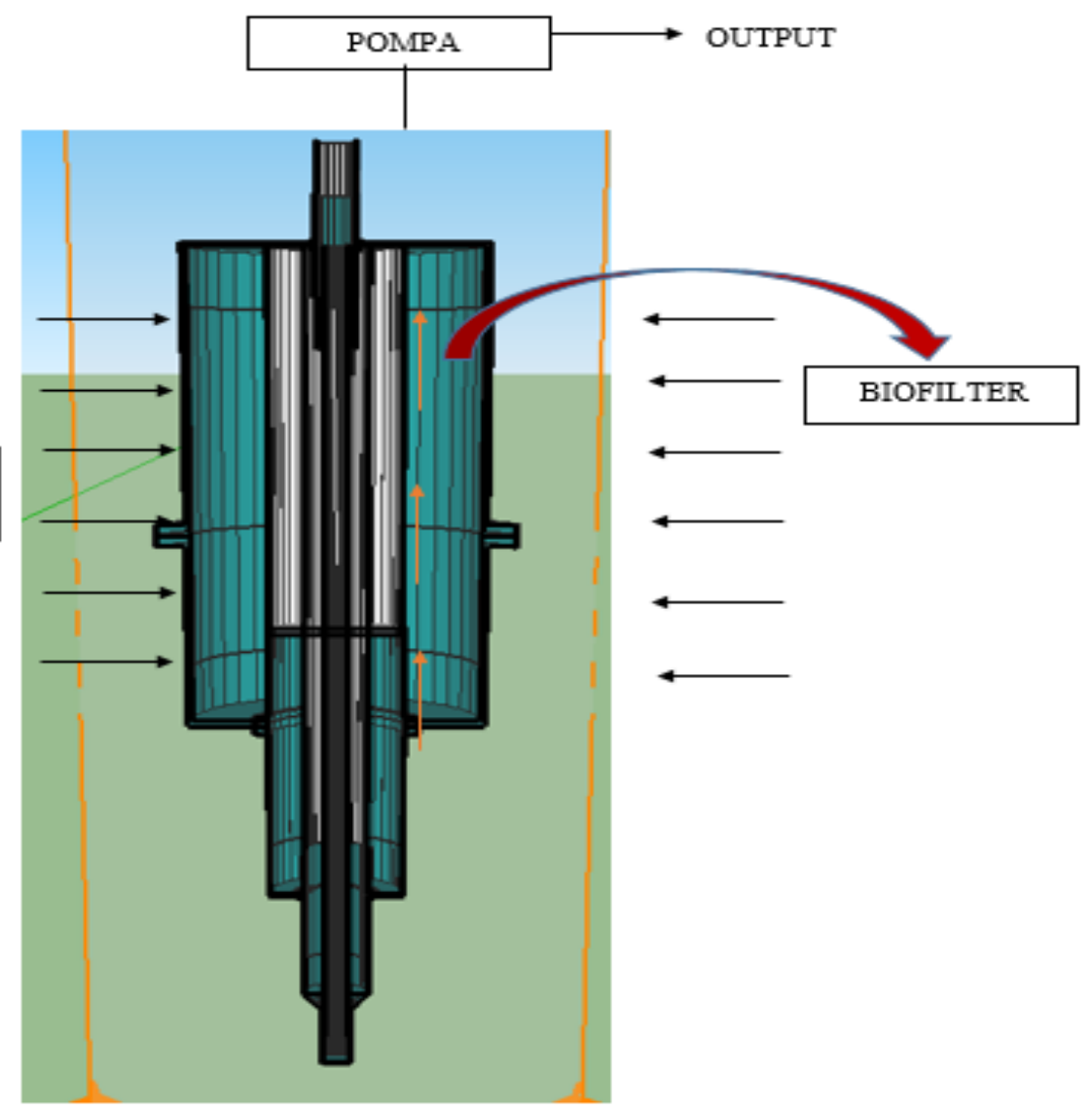

Gambar 2. Mekanisme/ Cara Kerja Alat

\section{KESIMPULAN DAN SARAN}

Adapun kesimpulan dari kegiatan Pemenuhan Kebutuhan Air Bersih di Desa Bukit Rawi, Kecamatan Kahayan Tengah, Kabupaten Pulang Pisau Melalui Penerapan
Teknologi Tepat Guna Penyaring Air Serbaguna Bio-Multi Filter Model Sarang Tawon ini adalah:

a. Masyarakat Desa Bukit Rawi sangat antusias terhadap kegiatan pengabdian 
kepada masyarakat yang dilakukan oleh Tim dari KBK Rekayasa Sumber Daya Air Jurusan/Program Studi Teknik Sipil Fakultas Teknik Universitas Palangka Raya.

b. Alat Penyaring Air yang ditawarkan dan diserahkan kepada masyarakat Desa Bukit Rawi adalah merupakan bentuk dari penerapan alih teknologi yang bermanfaat untuk masyarakat agar masyarakat bisa mendapatkan air bersih yang bening tidak bewarna dan tidak keruh.

c. Alat Penyaring Air bisa merupakan solusi untuk mendapatkan air bersih dari sumber air baku Sungai Kahayan.

Alat Penyaring Air yang telah diberikan kepada Desa Bukit Rawi agar tetap bisa digunakan secara terus menerus perlu diperhatikan perawatan dan pemeliharaannya.

\section{DAFTAR PUSTAKA}

Alamsyah, S. 2006. Merakit Sendiri Alat Penjernih Air Untuk Rumah Tangga. Jakarta. Kawan Pustaka.

Kusnaedi. 2010. Mengolah Air Kotor Untuk Air Minum. Jakarta. Penebar Swadaya.

Totok Sutrisno, C., dan Eni Suciastuti. 1991. Teknologi Penyediaan Air Bersih. Jakarta. Rineka Cipta.

\section{FOTO KEGIATAN}
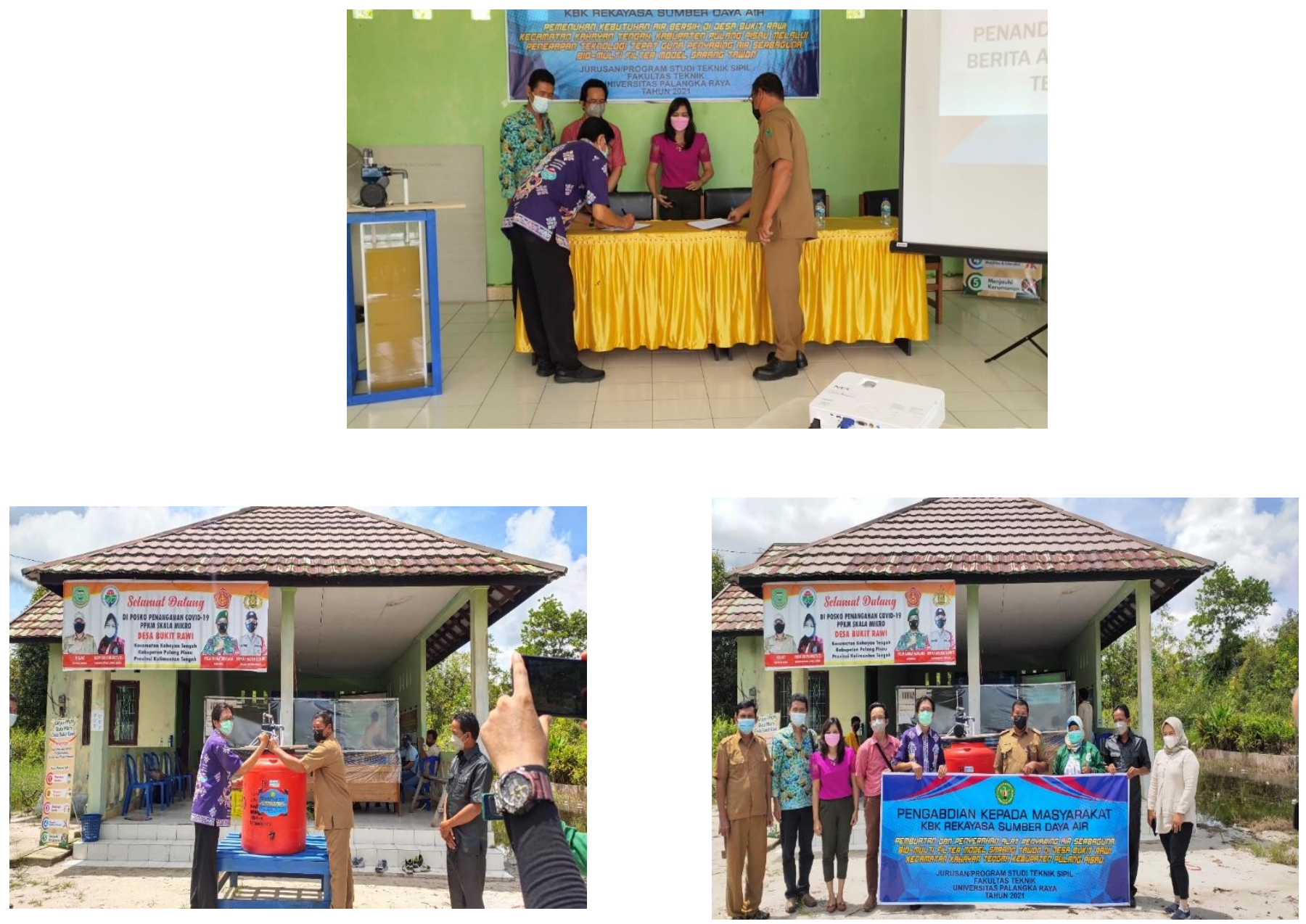

Kegiatan Penyerahan Penyaring Air di Depan Balai Desa Bukit Rawi 